E3S Web of Conferences 1, 08009 (2013)

DOI: $10.1051 / \mathrm{e} 3$ sconf/20130108009

(c) Owned by the authors, published by EDP Sciences, 2013

\title{
Modelling seasonal variations of natural radionuclides in agricultural soils
}

\author{
I. Guagliardi $^{1}$, G. Buttafuoco ${ }^{1}$, N. Ricca ${ }^{1}$, M. G. Cipriani, D. Civitelli, R. Froio, A. L. Gabriele and R. De Rosa ${ }^{2}$ \\ ${ }^{1}$ National Research Council of Italy- Institute for Agricultural and Forest Systems in the Mediterranean (ISAFOM), Via \\ Cavour 4/6, Rende (CS), Italy, ilaria.guagliardi@isafom-cnr.it; gabriele.buttafuoco@isafom-cnr.it; \\ nicola.ricca@isafom-cnr.it; \\ ${ }^{2}$ Department of Earth Sciences, University of Calabria, Ponte Pietro Bucci, 87036 Arcavacata di Rende - Cosenza \\ (Italy), derosa@unical.it
}

\begin{abstract}
Estimating activity of natural radionuclides in agricultural soil is very important for the protection of public health because the released radioactivity can enter the food chain. Radioactivity measurements were carried out in two different dates (winter and summer) in agricultural soil using a GRM-260 gamma-ray spectrometer. The study area (100 m x $100 \mathrm{~m}$ ) was an olive orchard in southern Italy. Measurements were carried out at 361 locations in January and July 2011. At the same locations, soil water content was measured to take into account the effect of soil moisture on radioactivity. A multi-Gaussian approach was used to explore and map the activity of naturally occurring radionuclides and soil water content for both seasons of measurements. The minimum radioactivity values were recorded in winter and the maximum values in summer, probably as a consequence of changes in weather and soil conditions (rainfall, soil moisture, temperature).
\end{abstract}

Key words: Soil, radionuclides, seasonality, olive orchard

\section{Introduction}

Radioactivity is omnipresent in the earth's crust in different amounts for both natural and man-made origin (Akhtar et al., 2005). Soil on the earth's crust is a source of radioactive risk, not only for continuous exposure to human being, but also, in case of agricultural soil, for the entry of radionuclides into the food chain and consequently into humans through the crops. At this regard soil-to-plant transfer constitutes one of the key processes, since in the long term the entry of radioelements into human food chains is controlled by the uptake of plant roots.

The amount of radioactivity in soil depends upon soil type and its uses, but also upon climate and particularly on thermal and rainfall regime of a region.

Quantifying temporal variability of gamma rays in soil is crucial for monitoring the available amount of radioactivity for crops.

Calabria Region has a Mediterranean climate, which is characterized by dry summers and relatively intense rains during spring and autumn. Soil properties in Calabria are intermediate between those of cold and subtropical climates (Llauradó et al., 1994). These characteristics produce an evident seasonality in radionuclides caused by the sharp contrasts in temperature and relative humidity (Baeza et al., 2001).

The objective of the study was to analyze the seasonal variations of activity for ${ }^{40} \mathrm{~K},{ }^{238} \mathrm{U}$ and ${ }^{232} \mathrm{Th}$ in an agricultural soil of southern Italy. In addition, seasonal variations of ${ }^{40} \mathrm{~K}$ and soil water content were interpolated and mapped to take into account the effect of soil moisture on radioactivity.

\section{Materials and Methods}

The study area $\left(10000 \mathrm{~m}^{2}\right)$ was located in an olive orchard in the southern Italy. In two different dates (January and July), called from now on winter and summer, measurements of radioactivity for three natural nuclides ${ }^{40} \mathrm{~K},{ }^{238} \mathrm{U},{ }^{232} \mathrm{Th}$ in soils were carried out in situ at 361 locations (Fig. 1) by means of the portable gamma-ray spectrometer GRM-260 (GF Instruments ${ }^{\circledR}$ ). Each measurement included the full spectrum of the natural gamma-radiation (counts per 4 minutes) and registered in 256 channels, each of which equal to 12 $\mathrm{keV}$. The counts were then transformed into activity of the corresponding radioactive elements. The spectrum is divided into four parts, groups of channels called ROI (Region Of Interest), in relation to the peak positions of 
studied radionuclides and due to the resolution of the scintillation detector. This instrument was designed for spectral measurements of natural and artificial radionuclides in field and laboratory conditions, giving information on the type and the concentration of radionuclides in rocks, soil and water.

Soil water content (SWC) was also measured using the reflectometer TRASE TDR System (Soilmoisture Equipment Corp.).

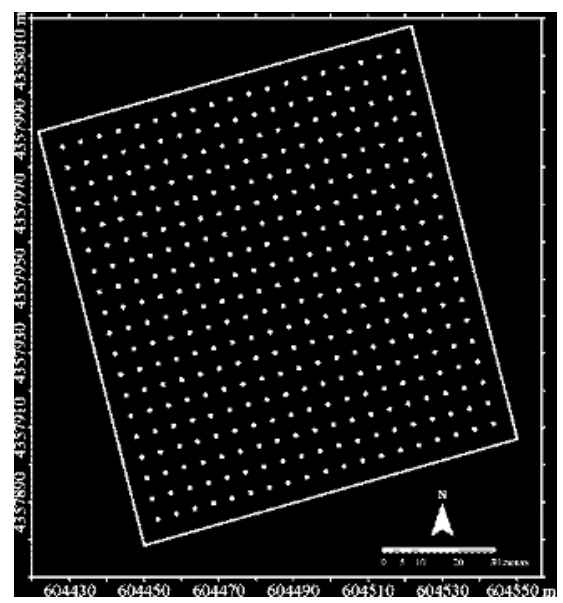

Fig. 1. Sample point locations

Gamma-ray measurements and soil water content can be regarded as regionalized variables (Matheron, 1971) and values at unsampled locations were predicted using the geostatistical methods. They provide a valuable tool for studying the spatial structure of radioactivity and SWC by taking into account the spatial autocorrelation in data to create mathematical models of spatial correlation structures commonly expressed by variograms. The Geostatistical methods are most efficient when carried out on variables that have Gaussian distributions, because a few exceptionally large or small values may contribute to several squared differences and inflate the average variance (Webster and Oliver, 2007). Gaussian anamorphosis (Wackernagel, 2003) allows one to transform a variable with a skewed distribution into a Gaussian variable regardless of the shape of the sample histogram. The kriging of such normalized data is referred to as multi-Gaussian kriging (Verly, 1983; Goovaerts, 1997; Wackernagel, 2003). It is based on a multi-Gaussian model and requires a prior Gaussian transformation of the initial attribute $\left\{Z(\mathbf{x}), \mathbf{x} \in R^{2}\right\}$ into a Gaussian-shaped variable $\left\{Y(\mathbf{x}), \mathbf{x} \in R^{2}\right\}$ with zero mean and unit variance. Ordinary multi-Gaussian kriging was used to predict radionuclides at unsampled locations. Ordinary multi-Gaussian kriging leads to a weakening of the stationary assumption and makes it robust to a departure of the data from the ideal stationary model (Emery, 2005).

Finally, the values of the Gaussian variables were estimated at the nodes of a $1 \mathrm{~m} \times 1 \mathrm{~m}$ interpolation grid and back-transformed using the inverse Gaussian anamorphosis.

\section{Results and Discussion}

Descriptive statistics of radioactivity and soil water content data for the two seasons are presented in Table 1. Radioactivity data ranged from 3.13 to 65.73 and from 3.13 to $115.81 \mathrm{~Bq} \mathrm{~kg}^{-1}$ for potassium, from 0.12 to 4.08 and from 0.05 to $7.41 \mathrm{~Bq} \mathrm{~kg}^{-1}$ for uranium, from 0 to 0.37 and from 0 to $0.45 \mathrm{~Bq} \mathrm{~kg}^{-1}$ for thorium in winter and summer respectively. Soil water content data ranged from 0.174 to 0.491 and from 0.960 to $0.287 \mathrm{~m}^{3} \mathrm{~m}^{-3}$ in winter and summer respectively. All

Table 1. Basic statistics of winter and summer activity for ${ }^{40} \mathrm{~K}\left(\mathrm{~Bq} \mathrm{~kg}^{-1}\right),{ }^{238} \mathrm{U}\left(\mathrm{Bq} \mathrm{kg}{ }^{-1}\right),{ }^{232} \mathrm{Th}\left(\mathrm{Bq} \mathrm{kg}^{-1}\right)$. Soil water content (SWC, $\mathrm{m}^{3} \mathrm{~m}^{-3}$ ) basic statistics are also reported.

\begin{tabular}{lcccc}
\hline \hline & ${ }^{40} \mathbf{K}$ & ${ }^{238} \mathbf{U}$ & ${ }^{232} \mathbf{T h}$ & SWC \\
\hline Min & 3.13 & 0.12 & 0 & 0.174 \\
Max & 65.73 & 4.08 & 0.37 & 0.491 \\
Mean & 13.59 & 0.76 & 0.17 & 0.350 \\
Median & 12.52 & 0.74 & 0.16 & 0.358 \\
Dev. St. & 8.60 & 0.39 & 0.06 & 0.473 \\
Kurtosis & 9.99 & 20.90 & 0.31 & 0.72 \\
Skewness & 2.66 & 3.49 & 0.46 & -0.10 \\
\hline & & \multicolumn{5}{c}{ Summer } \\
Min & 3.13 & 0.05 & 0 & 0.096 \\
Max & 115.81 & 7.41 & 0.45 & 0.287 \\
Mean & 18.95 & 0.83 & 0.16 & 0.164 \\
Median & 15.65 & 0.74 & 0.16 & 0.152 \\
Dev. St. & 15.26 & 0.51 & 0.06 & 0.045 \\
Kurtosis & 9.21 & 77.28 & 1.80 & 0.02 \\
Skewness & 2.64 & 6.73 & 0.56 & 0.95 \\
\hline \hline
\end{tabular}

The radionuclides activity shows a minimum in January and, as it was expected, precipitations increased soil water content and affected the changes in the apparent activities of ${ }^{40} \mathrm{~K},{ }^{238} \mathrm{U}$ and ${ }^{232} \mathrm{Th}$ in soil, even if the seasonal fluctuations of activity were minimal and they were more marked for ${ }^{40} \mathrm{~K}$ and less for ${ }^{238} \mathrm{U}$ and ${ }^{232}$ Th (see maximum values in Table 1 ). That was due to the low values of background radioactivity and consequently appreciable variations between the two seasons were minimal. However, lower radionuclides activities occurred during the winter when the radioactive gases are trapped near the surface, while in summer, the reduced soil water content allowed a greater level of radio-emission. In summer gases will move upward carrying radionuclides with them and thereby increasing ionization near to soil surface.

When soil water content was high for longer time periods, the gamma-radiation levels decreased, as a result 
of reduced rates of gas diffusion. The exhalation rate of the radioactive gases is dictated by the soil water content and is influenced by the soil permeability. Also the influence of air temperature seems to be important. Similar conclusions on the seasonal variations in the environmental gamma-radiation were reported in literature (Baciu, 2006; Lebedyte et al., 2003; Prasad et al., 2005; Yamazaki et al., 2002).

Hereafter only the results for ${ }^{40} \mathrm{~K}$ activity and soil water content are reported.

Data of winter and summer activity for ${ }^{40} \mathrm{~K}$ and soil water content (SWC) were transformed trough the Gaussian Anamorphosis. For each variate, a variogram map (not shown) was calculated and they did not show any significant difference as a function of direction. Results of variographic analysis for all variates are reported in Table 2. The experimental variogram for the Gaussian winter activity for ${ }^{40} \mathrm{~K}$ was modelled by a nested variogram that combines two basic structures (Table 2) including a nugget effect and a spherical model (Webster and Oliver, 2007) with a range of $6.5 \mathrm{~m}$. The nugget effect implies a positive intercept of the variogram. It arises from errors of measurement and spatial variation within the shortest sampling interval (Webster and Oliver, 2007). The range is a distance over which pairs of values are spatially correlated. The very short range value indicates that winter measured data of ${ }^{40} \mathrm{~K}$ activity are weakly structured.

For the Gaussian summer activity of ${ }^{40} \mathrm{~K}$, the experimental variogram was modelled by a nested variogram that combines three basic structures (Table 2): a nugget effect; a spherical model with a range of $12 \mathrm{~m}$, and a spherical model with a range of $58.80 \mathrm{~m}$ and. The two ranges indicate the presence of processes acting at different spatial scale (short and long range).

The experimental variogram for Gaussian winter data of soil water content was modelled by a nested variogram that combines three basic structures (Table 2) including a nugget effect, a short range exponential model with a range of $20.60 \mathrm{~m}$ and a long range spherical model with a range of $100 \mathrm{~m}$. Finally, the experimental variogram for Gaussian summer data of soil water content was modelled by a nested variogram that combines two basic structures (Table 2) including a nugget effect and a spherical model with a range of 18.60 $\mathrm{m}$.

Using the multi-Gaussian ordinary kriging, the Gaussian data of winter and summer activity for ${ }^{40} \mathrm{~K}$ and soil water content (SWC) were interpolated and mapped (Figs 2 and 3). In winter values of specific activity for ${ }^{40} \mathrm{~K}$ were very low, while in summer the high values of activity for ${ }^{40} \mathrm{~K}$ occurred in the right part of the field, which corresponds to the wettest areas. In winter soil water content was more homogeneous than summer and it would seem to determine the specific activity for ${ }^{40} \mathrm{~K}$ and its spatial pattern.

\section{Conclusion}

Monitoring an olive orchard using gamma-ray spectrometry allowed to analyze the seasonal variations of activity for ${ }^{40} \mathrm{~K},{ }^{238} \mathrm{U}$ and ${ }^{232} \mathrm{Th}$. Moreover, the effects of soil water content on radioactivity has been taken in account. Mapping soil water content and the activity for ${ }^{40} \mathrm{~K}$ allowed their spatial relationship.

Table 2. Variogram model parameters for Gaussian data of winter and summer activity for ${ }^{40} \mathrm{~K}$ and soil water content (SWC).

\begin{tabular}{llcc}
\hline \hline Variate & Model & Range (m) & Sill (-) \\
$\mathrm{G}^{40} \mathrm{~K}_{\text {winter }}$ & Nugget & - & 0.2780 \\
& Spherical & 6.50 & 0.4301 \\
$\mathrm{G}^{40} \mathrm{~K}_{\text {summer }}$ & Nugget & - & 0.4931 \\
& Spherical & 12.00 & 0.0795 \\
& Spherical & 58.80 & 0.3089 \\
$\mathrm{G} \mathrm{SWC}_{\text {winter }}$ & Nugget & - & 0.2619 \\
& Spherical & 20.60 & 0.5440 \\
& Spherical & 100.00 & 0.2226 \\
$\mathrm{G} \mathrm{SWC}_{\text {summer }}$ & Nugget & - & 0.3054 \\
& Spherical & 18.60 & 0.7597 \\
\hline \hline
\end{tabular}
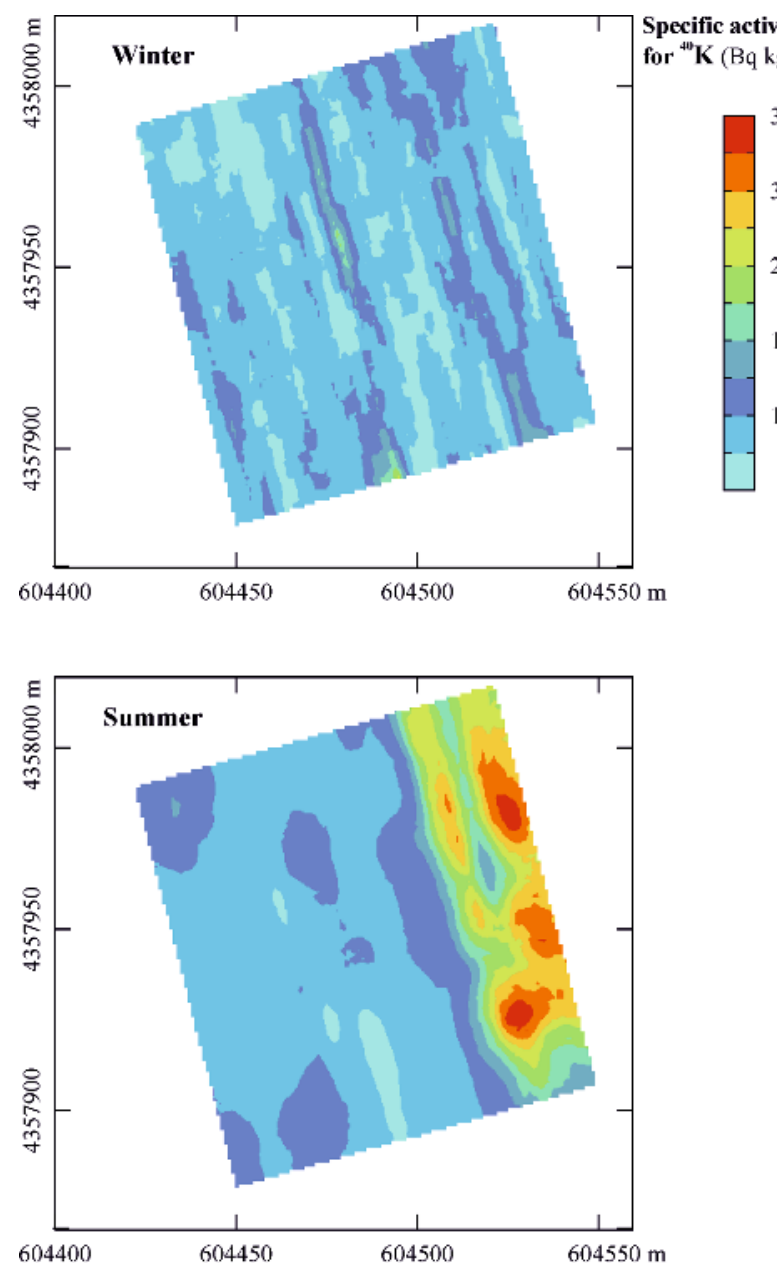

Fig. 2. Maps of specific activity for ${ }^{40} \mathrm{~K}$. 

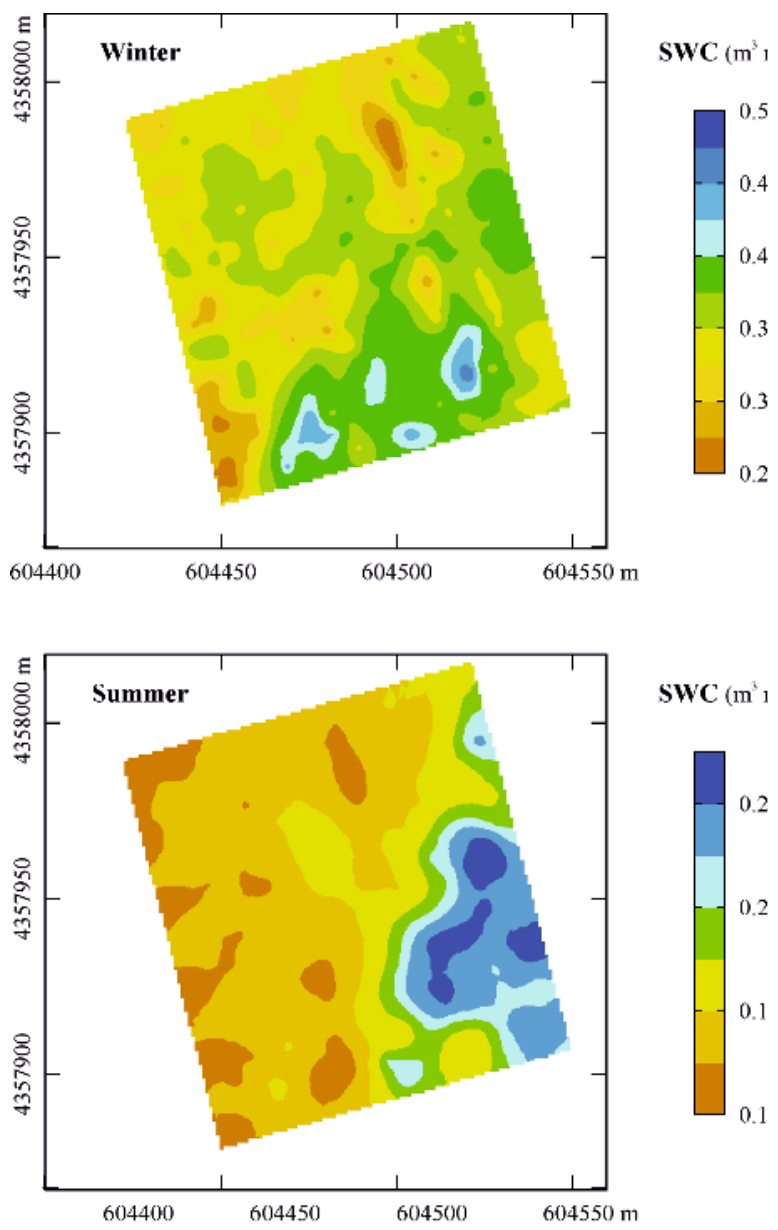

Fig. 2. Maps of soil water content.

\section{Acknowledgements}

This research was funded by the ACTION 2 - Public research laboratory mission oriented, APQ - Scientific Research and Technological Innovation in Calabria Region. Laboratory for Food Quality, Safety and Origin (QUASIORA).

\section{References}

Akhtara N, Tufail M, Ashraf M, Mohsin Iqbala M. 2005. Measurement of environmental radioactivity for estimation of radiation exposure from saline soil of Lahore, Pakistan. Radiat Meas 2005; 39: 11 - 14.

Baciu AC. Outdoor absorbed dose rate in air in relation to airborne natural radioactivity and meteorological conditions at Bucharest (Romania). J Radioanal Nucl Chem 2006; 268: 3-14.

Baeza A, Paniagua J, Rufo M, Guilléna J, Sterling A. Seasonal variations in radionuclide transfer in a Mediterranean grazing-land ecosystem. J Environ Radioact 2001; 55: 283-302.

Emery X. Simple and Ordinary Multigaussian Kriging for Estimating Recoverable Reserves. Math Geol 2005; 37: 295-319.

Goovaerts P.. Geostatistics for Natural Resources Evaluation. New York: Oxford University Press; 1997.

Lebedyte M, Butkus D, Morkūnas G. Variations of the ambient dose equivalent rate in the ground level air. J Environ Radioact 2003; 64: 45-57.

Llauradó M, Vidal M, Rauret G, Roca C, Fons J, Vallejo VR,. Radiocaesium behaviour in Mediterranean conditions. J Environ Radioact 1994; 23, 81-100.

Matheron G. The Theory of Regionalised variables and its Applications. Les Cahiers du Centre de Morphologie Mathématique de Fontainebleau 5; 1971.

Prasad BSN, Nagaraja K, Chandrashekara MS, Parameshn L, Madhava MS. Diurnal and seasonal variations of radioactivity and electrical conductivity near the surface for a continental location Mysore, India. Atmos Res 2005; 76: 65-77.

Webster R, Oliver M A. Geostatistics for Environmental Scientists. $2^{\text {nd }}$ Ed. Chichester: Wiley; 2007.

Verly G. The Multigaussian approach and its application to the estimation of local reserves. Math Geol 1983; 15: 259-286.

Wackernagel H. Multivariate Geostatistics: an introduction with Applications. Berlin: Springer-Verlag; 2003.

Yamazaki K, Tonouchi S, Hashimoto T. Factors associated with the variations in environmental gamma-ray spectra in Kashiwazaki Kariwa area. J Radioanal Nucl Chem 2002; 252: 359-36. 